\title{
Investigation of the Relationship Between Basic Swimming Instruction and Some Physical and Motor Characteristics
}

\author{
H. Bayram Temur \\ Correspondence: H. Bayram Temur, Yüzüncü Yıl University High School of Physical Education and Sports, Van, \\ Turkey.
}

Received: July 22, 2018

doi:10.11114/jets.v6i11.3465
Accepted: September 2, 2018

Online Published: September 12, 2018

URL: https://doi.org/10.11114/jets.v6i11.3465

\begin{abstract}
In this study, it was aimed to investigate whether basic swimming training has effects on height, body weight, right and left hand grip strength, right and left hand lengths, shoulder width, chest circumference, standing long jump characteristics. The study is important in terms of making individuals in the growth period and investigating the physical development of major technical studies from force studies. It is known that regular sport has also developed physical features along with many other features. However, there is not a complete consensus about the sport, its violence, its frequency and duration. The study using the experimental research method included 114 individuals with a mean age of $11.03 \pm 1.23$ years. The study group, consisting of 58 subjects, received regular swimming lessons twice a week for two hours at a time over a period of 7 months. The sedentary control group included 56 subjects who received no sports instruction apart from their standard physical education classes. Prior to the start of the study, measurements were taken for height, body mass, right and left hand grip strength, right and left hand length, shoulder width, chest circumference, and standing long jump for both groups. The same measurements were taken again 7 months later, at the conclusion of the study. The differences between the initial and final measurements of both the study group and the control group were statistically compared within the group and between the groups. In this comparison, the General Linear Model method was used in the SPSS 21 Package program. As a result, it was found that the increase in height, body weight, right hand grip strength, right and left hand lengths, chest circumference and standing long jump mean values of swimming training subjects were found to be different at $\mathrm{p}<0.001$ in the control group in seven months period. It was also found that the increase in the mean value of left hand grip strength in both groups was significantly different in favor of swimming training subjects $(\mathrm{p}<0.005)$. The increase in shoulder width mean values of the study group and the control group did not differ between the groups $(\mathrm{p}>0,005)$.
\end{abstract}

Keywords: swimming training, height, body weight, hand grip strength, hand lengths, shoulder circumference, chest circumference, long jump

\section{Introduction}

Swimming is the totality of movements that an individual makes in order to cover a given distance in the water. As a sport, swimming is defined as the ability of an athlete in to cover certain distances in the water in the shortest amount of time. Compared to other athletic activities, swimming has a lower risk of injury and contributes to the development of motor skills. In order to achieve high performance levels in swimming, the athlete needs to begin the sport at a young age, must be trained by a coach with good technical knowledge, and have the support of his/her family and school. If a swimmer wants to be successful in the sport, regular, high-quality training is necessary, along with adequate rest and good nutrition (Hanula, 2001).

The most distinctive difference of swimming sports is that the arms and legs with the same or separate use of the horizontal movement to make efforts to ensure. This activity is normal to the human organism and normal to other sports disciplines in a non-environment, in water and in an unusual position (horizantal) (Akgün 1994). There is also pressure effect on the breathing of the water which makes it difficult to breathe. For this reason, we can say that "the energy required to swim a distance is four times the energy required to run the same distance" (Odabaş, 2003).

Swimming provides the possibility of developing both the physical and psychological characteristics which form the basis for all types of athletic activities. By developing his/her skill, coordination, endurance, speed, swiftness, agility, flexibility, and mobility, a swimmer gains a feeling of self-confidence and the ability to compete, along with enjoying 
friendly play. The sport of swimming carries a separate importance as an athletic activity that aims to develop the individual's mental, psychological, sociological, and physiological development (Urartu, 1995).

In children, maximum oxygen consumption increases with age in both sexes. The slight increase which is observed between the ages of 9-13 accelerates in puberty and reaches its highest point at approximately age 14. The increase in maximal oxygen consumption exhibits a similarity with the increase in height and body mass (Rowland, 1990; Welsman and Armstrong, 2000).

Studies have shown that when age and sex are taken into consideration, swimmers who excel at the standing long jump are good sprinters, while those with low scores tend more towards distance swimming. Those who fall between these norms are good middle distance swimmers (Ylldız, 1998). Swimming is a branch of sports that includes many factors such as physical strength, technique, skill and coordination. Various factors play a role in the formation of a complex motoric trait. These include muscle types, muscle strength, anthropometric factors, flexibility, ability to relax muscles, psychological effects, warming (muscle warming), and muscle fatigue (Muratl1, 1997).

Muscle strength increases with age, and increase in muscle mass reaches its pinnacle in childhood. Strength has been shown to increase in girls up until the age of 15, after which, without exercise, a decrease is observed (Güler et al., 2004). At the same time, as age increases the transverse cross-sections of muscles draw nearer to each other. The reduction in muscle mass occurs much more rapidly, and lasts longer, in sedentary individuals (Zorba, 2001).

A critical aspect of athletic performance is development, which is tied to an increase in strength. Consciously performed strength exercises are believed to be useful, on condition that the important and varied aspects of athletic training for children are taken into account (Muratl1, 2007). Strength, as a fundamental component of athletic activities, forms the basis of performance in recreational activities. In addition, strength plays a crucial role in an individual's daily exercise regime producing effective results (Tamer, 1995).

Muscle strength increases with age in children; during puberty, there are clear increases in muscle strength. Improvement in sports that rely on muscle strength and speed occurs slowly with increasing age. Because of this, efforts to ensure early success by excessively pressuring children at very young ages may have negative effects on a child's physical growth (Y1lmaz 2001). The fundamental goal of studies on muscle strength used in swimming is to ensure the development of strength by employing movements appropriate for swimming and, therefore, the transfer of power to the water (Kraemer and Fleck, 2005).

One study concluded that a swimmer between the ages of 9-10, using either his/her own body weight or exercise equipment, may perform exercises that do not load weight on the joints in excess of $50 \%$ of his/her load intensity (Kılınç, 2003).

In this study, it was aimed to investigate whether swimming education has an extra contribution to physical growth levels of individuals in the age of growth (average age of $11.03 \pm 1.23$ years). For this, features such as height, body weight, right and left hand grip strength, right and left hand lengths, shoulder width, chest circumference, standing long jump were calculated separately as working and control groups for seven months before and after the process. The averages of the increase rates in both groups were compared and it was attempted to determine whether swimming training contributed to the improvement in individuals.

\section{Method}

\subsection{Participants}

A total of 114 boys of mean age $11.03 \pm 1.23$ years were enrolled in the study. A study group composed of 58 subjects received regular swimming instruction for a period of 7 months, twice a week, each lesson lasting two hours. The subjects were chosen from individuals who had never taken swimming lessons prior to the study. The control group consisting of 56 persons did not receive any sports education except physical education course. Both the working group and the control group consisted of male students from primary school. Descriptive information (table 1) before the study of both groups is given below.

Table 1. Descriptive data of the participants based on initial measurements

\begin{tabular}{lccccccc}
\hline \multirow{2}{*}{ Groups } & $\mathbf{N}$ & \multicolumn{2}{c}{ Age (year) } & \multicolumn{2}{c}{ Height (cm) } & \multicolumn{2}{c}{ Body weight (kg) } \\
\cline { 2 - 8 } & & Average & Standard deviation & Average & Standard deviation & Average & Standard deviation \\
\hline Swimming & 58 & 10,38 & 1,39 & 137,74 & 10,21 & 32,28 & 9,51 \\
Sedanter & 56 & 11,71 &, 45 & 148,73 & 6,37 & 41,70 & 7,54 \\
Total & 114 & 11,03 & 1,23 & 143,14 & 10,14 & 36,90 & 9,78 \\
\hline
\end{tabular}

\subsection{Precedure}

The study was planned on the assumption that a seven-month swimming training contributed to the physical development of children. For this purpose, about 90 elementary school students allowed by their parents among the primary school students were included in the study by taking their health reports. As a result of the seven-month 
swimming training, the measurements of 58 individuals who went on regular basis were taken again, taking into account the flow charts. On the other hand, the first measurements of 65 students without any disease among the primary school students were taken at the same time as the study group. They were not included in the study because they could not reach 9 of them after seven months. Body length, body weight, right and left hand grip strength, right and left hand lengths, shoulder width, chest circumference, standing long jump values were determined for participants included in the study. Seven months later the subject measurements were repeated. No intervention was made to feed the participants. They wanted to keep normal eating habits.

\subsection{Instruments and Measurements}

The height of the subjects was measured in meters, while body mass was measured using a sensitive scale (ANGEL USA). Chest circumference, shoulder width, and hand length were obtained using a tape measure. Right and left hand grip strength were measured using a Takkei Physical Fitness Test Grip-D (Grip Strength Dynamometer, Made in Japan) brand hand dynamometer.

\section{Measurement Methods:}

Height: Height was measured in meters, with the subjects standing upright in bare feet.

Body mass: Body weight was measured using a sensitive electronic scale, with the subjects in bare feet and wearing only gym shorts.

Right and left hand grip strength: The subjects gripped the device while standing without bending their elbows or touching their bodies. Measurements were repeated for each hand and the best measurement for each was recorded.

Chest circumference: Chest circumference was measured using a tape measure with the subject standing, arms in abduction position. The tape measure was placed at the level of the fourth rib and passed around the lower end of the scapula in the back. The measurement was taken under conditions of normal breathing after the subject had exhaled.

Hand length: Measured using a measuring tape, from the radial styloid to the tip of the middle finger, with the forearm in a horizontal position.

Shoulder width: The distance between the outermost parts of the right and left acromial processes, taken using a measuring tape while the subject was standing.

Standing long jump: The participants were asked to jump forward standing behind a starting line as far as possible using both legs. The distance jumped was measured in $\mathrm{cm}$ as the distance between the front of the starting line and the point where the heel touched the floor.

\subsection{Data Analysis}

The results were transferred to the computer environment. Statistical comparisons were made using the General Linear Model method in the SPSS 21.0 package program.

\section{Results}

Table 2. Range of pre- and post-test values of variables by group

\begin{tabular}{|c|c|c|c|c|c|c|}
\hline \multirow[t]{2}{*}{ Variables } & \multirow[t]{2}{*}{ Groups } & \multirow[t]{2}{*}{$\mathbf{N}$} & \multicolumn{3}{|c|}{ Pre-test } & \multirow{2}{*}{$\begin{array}{l}\text { Final test } \\
\text { Standard deviation } \\
\end{array}$} \\
\hline & & & Average & ard des & Average & \\
\hline \multirow{2}{*}{ Height $(\mathrm{cm})$} & Swimming & 58 & 137,74 & 10,21 & 142,26 & 10,73 \\
\hline & Sedanter & 56 & 148,73 & 6,37 & 152,91 & 6,29 \\
\hline \multirow[t]{2}{*}{ Body weight (kg) } & Swimming & 58 & 32,28 & 9,51 & 34,71 & 10,10 \\
\hline & Sedanter & 56 & 41,70 & 7,54 & 45,61 & 7,76 \\
\hline \multirow[t]{2}{*}{ Shoulder circumference $(\mathrm{cm})$} & Swimming & 58 & 34,96 & 3,30 & 42,23 & 3,79 \\
\hline & Sedanter & 56 & 38,39 & 2,76 & 38,91 & 2,44 \\
\hline \multirow[t]{2}{*}{ Chest circumference $(\mathrm{cm})$} & Swimming & 58 & 67,82 & 7,59 & 67,84 & 9,25 \\
\hline & Sedanter & 56 & 77,36 & 9,30 & 80,45 & 6,55 \\
\hline \multirow[t]{2}{*}{ Right hand grip force (kg) } & Swimming & 58 & 14,12 & 4,86 & 15,50 & 5,05 \\
\hline & Sedanter & 56 & 17,34 & 3,29 & 17,68 & 3,09 \\
\hline \multirow[t]{2}{*}{ Left hand grip force $(\mathrm{kg})$} & Swimming & 58 & 14,06 & 4,09 & 15,42 & 4,38 \\
\hline & Sedanter & 56 & 16,59 & 3,43 & 16,82 & 3,45 \\
\hline \multirow[t]{2}{*}{ Right hand length $(\mathrm{cm})$} & Swimming & 58 & 14,55 & 1,35 & 14,72 & 1,51 \\
\hline & Sedanter & 56 & 17,00 & ,92 & 17,68 & ,95 \\
\hline \multirow{2}{*}{ Left hand length $(\mathrm{cm})$} & Swimming & 58 & 14,59 & 1,24 & 14,86 & 1,53 \\
\hline & Sedanter & 56 & 17,03 & ,93 & 17,74 & 1,00 \\
\hline \multirow[t]{2}{*}{ Long jump (cm) } & Swimming & 58 & 118,07 & 21,14 & 124,12 & 24,83 \\
\hline & Sedanter & 56 & 137,73 & 16,80 & 127,68 & 17,19 \\
\hline
\end{tabular}


Table 3. Range of pre- and post-test height measurements for all participants and between groups

\begin{tabular}{|c|c|c|c|c|c|}
\hline $\begin{array}{l}\text { Source of } \\
\text { Variance }\end{array}$ & Sum of squares & Standard deviation & Squares Average & $\mathbf{F}$ & $\mathbf{p}$ \\
\hline Interview & 23137,264 & 113 & & & \\
\hline $\begin{array}{l}\text { Groups } \\
\text { (swimming /sedanter) }\end{array}$ & 6672,835 & 1 & 6672,835 & 45,392 &, 000 \\
\hline Error & 16464,429 & 112 & 147,004 & & \\
\hline In-group & 1536,196 & 114 & & & \\
\hline Pre-test-Final test & 1077,213 & 1 & 1077,213 & 263,798 &, 000 \\
\hline Group* Measurement & 1,634 & 1 & 1,634 &, 400 &, 528 \\
\hline Error & 457,349 & 112 & 4,083 & & \\
\hline Total & 21601,068 & 227 & & & \\
\hline
\end{tabular}

In Table 3, when pre- and post-test values for height of those who received swimming instruction and those who did not were examined, the difference between the groups was shown to be statistically significant, with the study group exhibiting greater change ( $\mathrm{F}(45.392), \mathrm{p}<0.01)$. However, no significant difference in pre- and post-test values for height was found for the participants taken as a whole $(\mathrm{F}(0.400), \mathrm{p}>0.05)$.

Table 4. Range of pre- and post-test body mass measurements for all participants and between groups

\begin{tabular}{lccccc}
\hline $\begin{array}{l}\text { Source of } \\
\text { Variance }\end{array}$ & Sum of squares & Standard deviation & Squares Average & F & $\mathbf{p}$ \\
\hline Interview & 23004,093 & 113 & & \\
Groups & $\mathbf{5 8 7 7 , 6 2 9}$ & $\mathbf{1}$ & $\mathbf{5 8 7 7 , 6 2 9}$ & $\mathbf{3 8 , 4 3 7}$ & $\mathbf{, 0 0 0}$ \\
(swimming /sedanter) & & & & \\
Error & 17126,464 & 112 & 152,915 & & \\
In-group & 883,377 & 114 & 573,831 & 230,714 &, 000 \\
Pre-test-Final test & 573,831 & $\mathbf{1}$ & $\mathbf{3 0 , 9 8 0}$ & $\mathbf{1 2 , 4 5 6}$ & $\mathbf{0 0 1}$ \\
Group* Measurement & $\mathbf{3 0 , 9 8 0}$ & 112 & 2,487 & & \\
Error & 278,566 & 227 & & \\
Total & 22120,716 & & & \\
\hline
\end{tabular}

In Table 4, comparing pre- and post-test results for body mass for those who had swimming instruction and those who did not, the differences between groups is shown to be statistically significant, with the study group having greater change $(\mathrm{F}$ (38.437), $\mathrm{p}<0.01)$. At the same time, the difference in pre- and post-test values for all participants considered together was also significant (F (12.456), $\mathrm{p}<0.01)$.

Table 5. Range of pre- and post-test values for shoulder width for all participants and between groups

\begin{tabular}{|c|c|c|c|c|c|}
\hline $\begin{array}{l}\text { Source of } \\
\text { Variance }\end{array}$ & Sum of squares & Standard deviation & Squares Average & $\mathbf{F}$ & $\mathbf{p}$ \\
\hline Interview & 1910,811 & 113 & & & \\
\hline $\begin{array}{l}\text { Groups } \\
\text { (swimming /sedanter) }\end{array}$ & ,133 & 1 & ,133 & ,008 & ,930 \\
\hline Error & 1910,678 & 112 & 17,060 & & \\
\hline In-group & 1740,458 & 114 & & & \\
\hline Pre-test-Final test & 842,489 & 1 & 842,489 & 353,233 & ,000 \\
\hline Group* Measurement & 630,840 & 1 & 630,840 & 264,494 & ,000 \\
\hline Error & 267,129 & 112 & 2,385 & & \\
\hline Total & 170,353 & 227 & & & \\
\hline
\end{tabular}

When the values in Table 5 were examined, although there was not a statistically significant difference in the change in shoulder width between the two groups $(\mathrm{F}(0.008), \mathrm{p}>0.01)$, we did observe a statistically significant difference for all participants considered as a whole ( $\mathrm{F}(264.494), \mathrm{p}<0.01)$. 
Table 6. Range of pre- and post-test chest circumferences for all participants and between groups

\begin{tabular}{|c|c|c|c|c|c|}
\hline $\begin{array}{l}\text { Source of } \\
\text { Variance }\end{array}$ & Sum of squares & Standard deviation & Squares Average & $\mathbf{F}$ & $\mathbf{p}$ \\
\hline Interview & 19574,618 & 113 & & & \\
\hline $\begin{array}{l}\text { Groups } \\
\text { (swimming /sedanter) }\end{array}$ & 6901,440 & 1 & 6901,440 & 60,992 &, 000 \\
\hline Error & 12673,178 & 112 & 113,153 & & \\
\hline In-group & 2768,186 & 114 & & & \\
\hline Pre-test-Final test & 142,094 & 1 & 142,094 & 6,376 & 013 \\
\hline Group* Measurement & 129,953 & 1 & 129,953 & 5,831 & ,017 \\
\hline Error & 2496,139 & 112 & 22,287 & & \\
\hline Total & 17078,479 & 227 & & & \\
\hline
\end{tabular}

Examining the values presented in Table 6, a significant difference in chest circumference was observed between individuals who received swimming instruction and those who did not $(\mathrm{F}(60.992), \mathrm{p}<0.01)$, as well as for all participants (F (5.831), p < 0.05).

Table 7. Right hand grip strength pre- and post-test values for all participants and between groups

\begin{tabular}{lccccc}
\hline $\begin{array}{l}\text { Source of } \\
\text { Variance }\end{array}$ & $\begin{array}{c}\text { Sum of } \\
\text { squares }\end{array}$ & $\begin{array}{c}\text { Standard } \\
\text { deviation }\end{array}$ & $\begin{array}{c}\text { Squares } \\
\text { Average }\end{array}$ & F & p \\
\hline Interview & 4275,079 & 113 & & & \\
Groups & $\mathbf{4 1 5 , 2 9 8}$ & $\mathbf{1}$ & $\mathbf{4 1 5 , 2 9 8}$ & $\mathbf{1 2 , 0 5 1}$ & $\mathbf{0 0 1}$ \\
(swimming /sedanter) & 3859,781 & 112 & 34,462 & & \\
Error & 114,244 & 114 & & & \\
In-group & 42,163 & 1 & 42,163 & 83,248 &, 000 \\
Pre-test-Final test & $\mathbf{1 5 , 3 5 6}$ & $\mathbf{1}$ & $\mathbf{1 5 , 3 5 6}$ & $\mathbf{3 0 , 3 1 9}$ & $\mathbf{0 0 0}$ \\
Group* Measurement & 56,725 & 112 &, 506 & & \\
Hata & 4160,835 & 227 & & & \\
Toplam & & & & & \\
\hline
\end{tabular}

According to the values in Table 7, the difference in right hand strength between the two groups was determined to be significant $(\mathrm{F}(12.051), \mathrm{p}<0.01)$, with the study group having greater values, as was the change in strength among all participants taken as whole ( $\mathrm{F}(30.319), \mathrm{p}<0.01)$.

Table 8. Left hand grip strength pre- and post-test values for all participants and between groups

\begin{tabular}{lccccc}
\hline $\begin{array}{l}\text { Source of } \\
\text { Variance }\end{array}$ & Sum of squares & Standard deviation & Squares Average & $\mathbf{F}$ & $\mathbf{p}$ \\
\hline Interview & 3517,126 & 113 & & & \\
$\begin{array}{l}\text { Groups } \\
\text { (swimming /sedanter) }\end{array}$ & $\mathbf{2 2 0 , 2 0 0}$ & $\mathbf{1}$ & $\mathbf{2 2 0 , 2 0 0}$ & $\mathbf{7 , 4 8 0}$ & $\mathbf{, 0 0 7}$ \\
Error & 3296,926 & 112 & 29,437 & & \\
In-group & 108,131 & 114 & & & \\
Pre-test-Final test & 36,052 & 1 & 36,052 & 74,617 &, 000 \\
Group* Measurement & $\mathbf{1 7 , 9 6 5}$ & $\mathbf{1}$ & $\mathbf{1 7 , 9 6 5}$ & $\mathbf{3 7 , 1 8 1}$ & $\mathbf{, 0 0 0}$ \\
Error & 54,114 & 112 &, 483 & & \\
Total & 3408,995 & 227 & & & \\
\hline
\end{tabular}

Examining to the values in Table 8, the difference in left hand strength between the two groups was determined to be significant $(\mathrm{F}(7.480), \mathrm{p}<0.05)$, with the study group having greater values, while the change in strength among all participants taken as whole was also significant $(\mathrm{F}(37.181), \mathrm{p}<0.01)$.

The values in Table 9 show that there was a significant difference in the change in right hand length between the two groups $(\mathrm{F}(161.064), \mathrm{p}<0.01)$, with the study group undergoing greater change, as well as among the participants as a whole $(\mathrm{F}(9.851), \mathrm{p}<0.05)$. 
Table 9. Range of right hand length pre- and post-test values for all participants and between groups

\begin{tabular}{|c|c|c|c|c|c|}
\hline $\begin{array}{l}\text { Source of } \\
\text { Variance }\end{array}$ & $\begin{array}{l}\text { Sum of } \\
\text { squares }\end{array}$ & $\begin{array}{l}\text { Standard } \\
\text { deviation }\end{array}$ & $\begin{array}{l}\text { Squares } \\
\text { Average }\end{array}$ & $\mathbf{F}$ & $\mathbf{p}$ \\
\hline Interview & 704,969 & 113 & & & \\
\hline $\begin{array}{l}\text { Groups } \\
\text { (swimming /sedanter) }\end{array}$ & 415,819 & 1 & 415,819 & 161,064 & ,000 \\
\hline Error & 289,150 & 112 & 2,582 & & \\
\hline In-group & 55,461 & 114 & & & \\
\hline Pre-test-Final test & 10,316 & 1 & 10,316 & 27,845 & 000 \\
\hline Group* Measurement & 3,650 & 1 & 3,650 & $\mathbf{9 , 8 5 1}$ &, 002 \\
\hline Error & 41,495 & 112 &, 370 & & \\
\hline Total & 649,508 & 227 & & & \\
\hline
\end{tabular}

Table 10. Range of left hand length pre- and post-test values for all participants and between groups

\begin{tabular}{|c|c|c|c|c|c|}
\hline $\begin{array}{l}\text { Source of } \\
\text { Variance }\end{array}$ & Sum of squares & Standard deviation & Squares Average & $\mathbf{F}$ & $\mathbf{p}$ \\
\hline Interview & 699,128 & 113 & & & \\
\hline $\begin{array}{l}\text { Groups } \\
\text { (swimming /sedanter) }\end{array}$ & 404,476 & 1 & 404,476 & 153,745 &, 000 \\
\hline Error & 294,652 & 112 & 2,631 & & \\
\hline In-group & 47,081 & 114 & & & \\
\hline Pre-test-Final test & 13,716 & 1 & 13,716 & 49,976 &, 000 \\
\hline Group* Measurement & 2,628 & 1 & 2,628 & 9,575 &, 002 \\
\hline Error & 30,737 & 112 & ,274 & & \\
\hline Total & 652,047 & 227 & & & \\
\hline
\end{tabular}

As shown by the values in Table 10, there was a significant difference in the change in left hand length between the two groups $(\mathrm{F}(153.745), \mathrm{p}<0.01)$, with the study group exhibiting greater change, and also among the participants as a whole ( $\mathrm{F}(9.575), \mathrm{p}<0.05)$.

Table 11. Range of standing long jump pre- and post-test values for all participants and between groups

\begin{tabular}{|c|c|c|c|c|c|}
\hline $\begin{array}{l}\text { Source of } \\
\text { Variance }\end{array}$ & Sum of squares & Standard deviation & Squares Average & $\mathrm{F}$ & $\mathrm{p}$ \\
\hline Interview & 84898,72 & 113 & & & \\
\hline $\begin{array}{l}\text { Groups } \\
\text { (swimming /sedanter) }\end{array}$ & 7681,486 & 1 & 7681,486 & 11,142 & ,001 \\
\hline Error & 77217,234 & 112 & 689,440 & & \\
\hline In-group & 19101,017 & 114 & & & \\
\hline Pre-test-Final test & 228,140 & 1 & 228,140 & 1,683 & , 197 \\
\hline Group* Measurement & 3695,035 & 1 & 3695,035 & 27,266 &, 000 \\
\hline Error & 15177,842 & 112 & 135,516 & & \\
\hline Total & 65797,703 & 227 & & & \\
\hline
\end{tabular}

When the standing long jump values in Table 11 were examined, the difference in the change between the two groups was demonstrated to be significant $(\mathrm{F}(11.142), \mathrm{p}<0.01)$, the study group showing greater change, as was the difference between pre- and post-test values for all participants taken together $(\mathrm{F}(27.266), \mathrm{p}<0.05)$

\section{Discussion and Conclusion}

This study demonstrated that 7 months of basic swimming instruction positively affected anthropometric characteristics, hand grip strength, and standing long jump of children whose mean age was $11.03 \pm 1,23$ years. The fact that the present study was conducted on 11-year-olds who are still growing, its 7-month duration, and its comparison of the development of the study group with a sedentary control group add to the importance of this study.

When the change in mean height over the course of seven months was examined in the test subjects, no significant change was found among the participants taken as a whole ( $F(0.400), p>0.05)$. However, there was a statistically significant difference in the change in height between the study group and the control group ( $\mathrm{F}(45.392), \mathrm{p}<0.01)$, with the former exhibiting a greater increase in height. Akgün (1994), in a study conducted in the U.S., determined that swimmers were taller than sedentary individuals. While the increase in average height observed for all participants taken together is a natural outcome of growth and maturation, the statistically significant difference in the increase in height between the two groups may be connected to stretching exercises performed in swimming. Yörükoğlu and Koz (2007) determined that the increase in height in children extends from birth to maturation. Sklad et al. (1993) recorded a significant increase in height in both males and females aged 16-20.

When the average body mass values of the participants were examined, significant differences were found both between pre- and post-test measurements for all participants as a whole $(\mathrm{F}(12.456), \mathrm{p}<0.01)$, as well as between the groups $(\mathrm{F}$ 
(38.437), $\mathrm{p}<0.01)$. There was an increase in body mass between pre- and post-test values. The reason for this significant difference in pre- and post-test value for all participants is the natural outcome of growth and development, while the difference between the groups is thought to result from the effect of the additional growth and development of muscle mass due to swimming. In their study of 7-year-old boys, Zsofia and Janos (2007) determined that the difference in pre- and post-test weight was significant. The results of the present study align with those of their study.

When the difference in shoulder width was examined, it was found that the difference between pre- and post-test values for all participants was significant ( $\mathrm{F}(264.494), \mathrm{p}<0.01)$, while the difference between the groups was not ( $\mathrm{F}(0.008)$, $\mathrm{p}>0.01$ ). The increase in shoulder width of individuals in both groups who participated in the study can be explained by the fact that they are in a period of physical development; however, the difference in the increase in shoulder width in subjects who received swimming instruction in relation to the sedentary group is statistically significant can be attributed to the positive effects of participating in an athletic activity. Sklad et al. (1993), in their study which lasted a full year, found a significant difference in pre- and post-test values of shoulder width for both men and women.

After evaluating the mean values for chest circumference for all participants as a whole and between groups, the differences were shown to be statistically significant in both cases (F (5.831), p < 0.05 and $F(60.992), p<0.01$, respectively), with the study group having the greater change. Sklad et al. (1993) reported that there was no statistically significant difference in the increase in chest circumference values in male and female rowers aged 16-20. The reason that our results contradict those of the aforementioned study may be due to the different age groups of the two studies, as well as the fact that its subjects were rowers as opposed to swimmers.

The change in mean values for right hand grip strength was determined to be significant for all participants taken together ( $\mathrm{F}(30.319), \mathrm{p}<0.01)$, as well as between groups ( $\mathrm{F}(12.051), \mathrm{p}<0.01)$, with the study group showing greater change. In addition, at a p-level of $<0.01$, the average change in left hand grip strength for all participants was $F$ (37.181), while the difference in the change between groups was significant F (7.480), with $\mathrm{p}<0.05$. Again, the study group, which received swimming instruction, showed greater change. Seiler et al. (2006) reported a significant increase between the pre- and post-test values for hand grip strength in their study conducted with 13-year-old swimmers. Odabaş1 (2003) found a significant difference between pre- and post-test values for hand grip strength in 12-year-old subjects who participated in a 12-week swimming training program. While the difference between pre- and post-test values for all participants considered as a whole is thought to be a result of growth and maturation, it is accepted that training done in opposition to water resistance has positive effects on a person's strength and coordination. Y1lmaz et al. (2004) in their study of autistic children asserted that swimming instruction had a positive effect on hand grip strength.

The difference in pre- and post-test mean values for right hand length was found to be significant for all participants taken as a whole ( $\mathrm{F}(9.851), \mathrm{p}<0.05)$, as was the difference in change between the groups, with the study group exhibiting greater change $(\mathrm{F}(161.064), \mathrm{p}<0.01)$. The change in left hand length was shown to be significant for all participants $(\mathrm{F}$ (9.575), $\mathrm{p}<0.05)$, and the difference in change between groups was also significant $(\mathrm{F}(153.745), \mathrm{p}<0.01)$. In their study of rowers aged 16-20, Sklad et al. (1993) reported a significant increase in the length of upper extremities in female rowers.

When the mean values for standing long jump were examined, the difference between the pre- and post-test values for all participants considered together was significant $(\mathrm{F}(11.142), \mathrm{p}<0.01)$. The difference in change between the groups was shown to be significant as well, with the study group demonstrating a greater increase ( $F(27.266), p<0.05)$. In their study of autistic children, Yllmaz et al. (2004) determined that there was a significant difference in their standing long jump values taken prior to and following swimming instruction. This can be explained by the fact that, due to water resistance, kicking motions in the water develop quadriceps and hamstrings, along with other leg muscles, which are all instrumental in jumping.

It can be seen as the limitations of the study that the eating habits of the individuals participating in the study may not be determined and not intervened. Even if the groups have the same economic level, it would be more appropriate to abolish this limit. It can be said that basic education in swimming during the period of physical growth in the data obtained from the study contributes beyond the normal physical growth of the individuals in this period. In addition to the benefits of swimming at all ages, especially during the period of physical growth, it will contribute to the physical development of our children. It is a generation that is self-confident, psychologically sound, and able to build better social relationships. To achieve this, the family community and the state must hand in hand. All publications have to be conscious of the society. Physical conditions and curriculum that can be taught compulsory in educational institutions of swimming sports should be prepared. 


\section{References}

Akgün, N. (1994). Exercise and Sports physiology, Ege University Press, 5th edition, 1, Izmir, 46-47.

Güler, D., Balcı, S. S., Çolakoğlu, F., \& Karacan, S. (2004). 8-10 age group about health with Turkish girl the use and norms of physical fitness. Mehmet Akif Ersoy University Journal of Education Faculty, 5(2), 157-164.

Günata, G. P., \& İnce, G. (2010). The age group of 9-12 years on children's motor functions and reaction times 12 the effects of weekly basic badminton training exercises, 11th International Sport Science Congress, November 10-12, Antalya Turkey

Hanula, D. (2001). The Swim Coaching Bible. Human Kinetics; 21-133. I www.humankinetics.com was reached on 25 th May 2017.

Kilinc, F. (2003). Analysis of Some Factors Affecting Performance End-of-Training Training Program Activity. Doctoral Thesis. Kocaeli University Health Sciences Institute. Izmit.

Kraemer, J. W., \& Fleck, J. S. (2005). Strength training for young athletes, Second Edition, Human Kinetics, 25, 267-268.

Muratlı, S. (1997). Children and Sports, Ankara, Bagırgan Publishing House, 30-31, 169-183.

Muratl1, S. (2007). Children and Sport through the Training Science Approach. Ankara. Nobel Publications.

Odabaş, B. (2003). 12 Weekly Swimming Basic Education Studies 7-12 Yas Group Boys and Girls Effect on Physical and Motorsal Characteristics, Kocaeli, Kocaeli University Health Sciences Institute, Graduate Thesis,

Rowland, T. W. (1990). Development aspects of physiological functioning related to aerobic exercise in children, Sports Med., 10, 255-266.

Seiler, S., De Koning, J. J., \& Foster, C. (2006). The fall and rise of the gender difference in elite swimmers anaerobic performance. Med journal of sports England.

Sklad, M., Krawczyk, B., \& Majle, B. (1993). Effect of an intense annual training on body components and other somatic traits in young male and female rowers. Biology of Sport, 10, 4.

Tamer K. (1995). Measuring physical physiological performance and. Ankara. Turkerler Publisher.

Urartu U. (1995). Swimming Technical Tactics and Condition, İstanbul, İnkılap Bookstore, 9-12.

Welsman, J. R., \& Armstrong, N. (2000). Longitudinal changes in submaximal oxygen uptake in 11 to $13 y e a r$ olds, Journal of Sports Sciences, 18, 183-189. https://doi.org/10.1080/026404100365081

Y1ldız, M. (1998). Physics and Physiology of Children Participating in the Summer Sports School Swimming Program Investigation of Capacities Malatya, İnönü University Health Sciences Institute, Master Thesis,

Yilmaz, F. (2001). Comparison of Football Teams' Substructures in terms of Technical and Motoric Ability. Graduate Thesis Sakarya University Social Sciences Institute. Sakarya.

Yılmaz, İ. Yanardag, M., Birkan, B., \& Bumin, G. (2004). Effects of swimming training on physical fitness water orientation in autism. Pediatrics International, 46, 624-626. https://doi.org/10.1111/j.1442-200x.2004.01938.x

Yörükoğlu, U., \& Koz, M. (2007). 10-13 years of basketball workouts with sports school studies effect on physical, physiological and anthropometric properties of male children. Spormeter Journal of Physical Education and Sports Sciences, 5(2), 79-83.

Zsofia, A., \& Janos, T. (2007). Swimming training after changes of body seven years old boys. J. Physiol. Anthropol., Romania.

Zorba, E. (2001). Physical Fitness. Ankara. Gazi Bookshop, 166.

\section{Copyrights}

Copyright for this article is retained by the author(s), with first publication rights granted to the journal.

This is an open-access article distributed under the terms and conditions of the Creative Commons Attribution license which permits unrestricted use, distribution, and reproduction in any medium, provided the original work is properly cited. 